\title{
MKR mice have increased dynamic glucose disposal despite metabolic inflexibility, and hepatic and peripheral insulin insensitivity
}

\author{
B. Vaitheesvaran • D. LeRoith • I. J. Kurland
}

Received: 30 December 2009/Accepted: 26 April 2010/Published online: 25 June 2010

(C) Springer-Verlag 2010

\begin{abstract}
Aims/hypothesis Recent work has shown that there can be significant differences when glucose disposal is assessed for high-fat induced insulin resistance by static clamp methods vs dynamic assessment during a stable isotope i.p. glucose tolerance test. MKR mice, though lean, have severe insulin resistance and decreased muscle fatty acid oxidation. Our goal was to assess dynamic vs static glucose disposal in MKR mice, and to correlate glucose disposal and muscle-adipose-liver flux interactions with metabolic flexibility (indirect calorimetry) and muscle characteristics. Methods Stable isotope flux phenotyping was performed using $\left[6,6-{ }^{2} \mathrm{H}_{2}\right]$ glucose, $\left[\mathrm{U}^{-13} \mathrm{C}_{6}\right]$ glucose and $\left[2-{ }^{13} \mathrm{C}\right]$ glycerol. Muscle triacylglycerol (TAG) and diacylglycerol (DAG) content was assessed by thin layer chromatography, and histological determination of fibre type and cytochrome $c$ activity performed. Metabolic flexibility was assessed by indirect calorimetry.

Results Indirect calorimetry showed that MKR mice used more glucose than $\mathrm{FVB} / \mathrm{N}$ mice during fasting (respiratory exchange ratio [RER] 0.88 vs 0.77 , respectively). Compared with FVB/N mice, MKR mice had faster dynamic glucose disposal, despite increased whole-muscle DAG and
\end{abstract}

B. Vaitheesvaran · I. J. Kurland $(\bowtie)$

Department of Medicine, Albert Einstein College of Medicine, 1301 Morris Park Ave,

Bronx, NY 10461, USA

e-mail: irwin.kurland@einstein.yu.edu

D. LeRoith

Mount Sinai School of Medicine,

New York, NY, USA
TAG, and similar hepatic glucose production with higher fasting insulin and unchanged basal glucose. Fed MKR muscle had more glycogen, and increased levels of GLUT1 and GLUT4 than FVB/N muscle. Histology indicated that MKR soleus had mildly decreased cytochrome $c$ activity overall and more type II (glycolytic) fibres compared with that in $\mathrm{FVB} / \mathrm{N}$ mice.

Conclusions/interpretation MKR muscle adapts to using glucose, with more type II fibres present in red muscle. Fasting RER is elevated and glucose disposal during an i.p. glucose tolerance test is accelerated despite increased muscle DAG and TAG. Metabolic inflexibility may result from the compensatory use of fuel that can be best utilised for energy requirements; static vs dynamic glucose disposal assessments may measure complementary aspects of metabolic flexibility and insulin sensitivity.

Keywords Calorimetry · Fibre-type - Glucose disposal · Glycogen · Hepatic glucose production - Insulin resistance . Metabolic flexibility $\cdot$ Metabolomics $\cdot$ Respiratory exchange ratio $\cdot$ Stable isotopes

$\begin{array}{ll}\text { Abbreviations } \\ \text { DAG } & \text { Diacylglycerol } \\ \text { DN } & \text { Dominant negative } \\ \text { GC/MS } & \text { Gas chromatography/mass spectrometry } \\ \text { HGP } & \text { Hepatic glucose production } \\ \text { PPAR } & \text { Peroxisome proliferator-activated receptor } \\ \text { RER } & \text { Respiratory exchange ratio } \\ \text { SipGTT } & \text { Stable isotope i.p. glucose tolerance test } \\ \text { TAG } & \text { Triacylglycerol } \\ \text { TLC } & \text { Thin layer chromatography }\end{array}$




\section{Introduction}

MKR mice overexpress a dominant negative (DN) (Lys to Arg substitution) mutant IGF-1 receptor specifically in skeletal muscle under the control of the promoter for the gene encoding muscle creatine kinase. The resultant DN-IGF-1insulin receptor hybrids have inhibited downstream signalling, which leads to muscle insulin resistance $[1,2]$. MKR mice have early development of type 2 diabetes mellitus with severe insulin resistance as measured by the euglycaemic-hyperinsulinaemic clamp [1]. MKR mice display hyperinsulinaemia as early as 2 weeks of age and have significantly increased serum lipids (NEFA and triacylglycerol [TAG]), indicating adipose insulin resistance. This is followed by a compensatory increase in beta cell insulin secretion, leading to liver insulin resistance at 3 weeks with increased glucose output by the liver, impaired muscle fatty acid utilisation and euglycaemichyperinsulinaemic clamp measurements of insulinstimulated glucose disposal, and eventual beta cell decompensation $[1,3]$.

Previously we have shown in the chow-fed Ppara (also known as Ppara)-null mouse that a diminished capacity to utilise fatty acids results in a compensatory increase in glucose disposal, as assessed by a stable isotope i.p. glucose tolerance test (SipGTT) [4]. Insulin-stimulated glucose disposal in high-fat fed Ppar -null mice cannot be distinguished from that in SV129J wild-type mice during a euglycaemic or hyperglycaemic clamp [5, 6]. However, recently, we have shown that glucose disposal is also greater in high-fat fed Ppar $\alpha$-null mice when assessed using a SipGTT [6]. Since MKR mice also have decreased muscle fatty acid oxidation, ameliorated by the administration of peroxisome proliferator-activated receptor (PPAR) $\alpha$ agonists [3], we chose to examine static vs dynamic differences in glucose disposal in the MKR mouse.

Our purpose was to assess dynamic fuel utilisation interactions and compensations in MKR mice using stable isotope flux phenotyping. Dynamic assessment of glucose disposal using a SipGTT) and indirect calorimetry for fuel utilisation revealed that MKR mice have a unique form of metabolic inflexibility, in which carbohydrate is preferred despite hyperlipidaemia. Histological assessments of MKR muscle suggested that muscle fibre adaptations for increased glucose usage occur. We propose that static (euglycaemic-hyperinsulinaemic clamp measurements) vs dynamic (SipGTT measurements) components of glucose disposal may both be independent measurements of in vivo whole-body insulin sensitivity and metabolic flexibility. Metabolic inflexibility may result from the compensatory use of alternative fuel substrates to maintain overall fuel needs.

\section{Methods}

Animals Male MKR and FVBN wild-type mice aged 4 to 5 months old were housed in a full-barrier facility with a 12-h light/dark cycle (07:00 hours/19:00 hours) for all studies. They had full access to standard chow (4\% Mouse/ Rat Diet, catalogue number 7001; Harlan Teklad, Frederick, MD, USA) and water unless otherwise stated. Generation and characterisation of MKR mice have been described previously [1]. Homozygous MKR male mice (FVB/N background) were used at 4 to 5 months of age. Wild-type littermates on $\mathrm{FVB} / \mathrm{N}$ background were used as controls. All animal experiments were performed in accordance with National Institutes of Health guidelines and with the approval of the Animal Care and Use Committee of Mount Sinai School of Medicine (New York City), Albert Einstein College of Medicine and The State University of New York (Stony Brook).

Stable isotope flux phenotyping Studies were performed using the following stable isotopes: $\left[6,6{ }^{2} \mathrm{H}_{2}\right]$ glucose (i.p. GTT), $\left[\mathrm{U}_{-}{ }^{13} \mathrm{C}_{6}\right.$ ]glucose (hepatic glucose production [HGP]) and $\left[2-{ }^{13} \mathrm{C}\right]$ glycerol (glycerol production). Blood samples were analysed using gas chromatography/mass spectrometry (GC/MS) (for operation details, see our previous studies $[4,6-10])$.

Stable isotope-labelled glucose tolerance test studies For the SipGTT studies, five MKR and six FVB/N wild-type mice were used. Dynamic glucose disposal was assessed by determining the disappearance rate of $\left[6,6-{ }^{2} \mathrm{H}_{2}\right]$ glucose. Briefly, mice were fasted from 19:00 hours. At 10:00 hours next morning, [6,6- $\left.{ }^{2} \mathrm{H}_{2}\right]$ glucose was injected i.p. $(1.0 \mathrm{mg} / \mathrm{g}$ body weight, containing $50 \%\left[6,6{ }^{2} \mathrm{H}_{2}\right]$ glucose). Blood samples for insulin and glucose analysis were collected by retro-orbital bleed at time zero (before injection of $\left[6,6-{ }^{2} \mathrm{H}_{2}\right]$ glucose) and at 30,60 and 120 min after injection. Each time-point of the SipGTT is based on the average of five mice, with each mouse being bled twice ( 0 and $60 \mathrm{~min}$, or 30 and $120 \mathrm{~min}$ ) and a total of ten mice used per SipGTT. $\left[6,6-{ }^{2} \mathrm{H}_{2}\right]$ Glucose was $>98 \%$ enriched and tested for sterility and pyrogenicity by the manufacturer (Cambridge Isotope Laboratories, Andover, MA, USA).

Stable isotope assessment of in vivo lipolysis (glycerol production), and hepatic glucose production and clearance Glycerol production representing in vivo lipolysis was assessed using $\left[2-{ }^{13} \mathrm{C}\right]$ glycerol [7]. Static basal glucose disposal, which is equal to HGP in the fasted state, was determined by $\left[\mathrm{U}_{-}{ }^{13} \mathrm{C}_{6}\right]$ glucose. A constant infusion of either $\left[2-{ }^{13} \mathrm{C}\right]$ glycerol or $\left[\mathrm{U}_{-}{ }^{13} \mathrm{C}_{6}\right]$ glucose $(99 \%$ enriched; Cambridge Isotope Laboratories) was made through a miniosmotic pump (2001D; Durect, Cupertino, CA, USA ) over 
$24 \mathrm{~h}$ [7]. Briefly, fasting of animals was initiated at 16:00 hours and mini-osmotic pumps containing either $0.33 \mathrm{mg} / \mu \mathrm{l}\left[2-{ }^{13} \mathrm{C}\right]$ glycerol or $0.25 \mathrm{mg} / \mu \mathrm{l}$ of $\left[\mathrm{U}_{-}{ }^{13} \mathrm{C}_{6}\right]$ glucose were quickly inserted into the subcutaneous space of the mice 19:00 hours under $\sim 5 \%$ isoflurane. Blood samples were collected by orbital bleeding at 10.00 hours next morning.

Calculations Glycerol production ( $\mathrm{mg} \mathrm{min}^{-1} \mathrm{~kg}^{-1}$ ) representing in vivo lipolysis was calculated using the following equation. Glycerol production=infusion rate $\times$ $\left(1 / E^{\mathrm{gly}} \operatorname{Tracer}^{-}-1\right)$, where $E^{\mathrm{gly}}$ Tracer is the enrichment of plasma $\left[2-{ }^{13} \mathrm{C}\right]$ glycerol determined by $\mathrm{GC} / \mathrm{MS}$ analysis. The infusion rate $\left(\mathrm{mg} \mathrm{kg}^{-1} \mathrm{~min}^{-1}\right)$ was: mini-osmotic pump rate $\times\left[2-{ }^{13} \mathrm{C}\right]$ glycerol concentration $(0.33 \mathrm{mg} / \mu \mathrm{l}) /$ mouse body weight $(\mathrm{kg})$; the mini-osmotic pump rate was $8 \mu \mathrm{l} / \mathrm{h}$, and was calibrated by the manufacturer.

Hepatic glucose production rate was determined using the following equation: HGP (mg $\left.[\mathrm{kg} \text { body weight }]^{-1} \mathrm{~min}^{-1}\right)=$ infusion rate $\times\left(1 / \mathrm{E}^{\mathrm{glu}} \operatorname{Tracer}^{-} 1\right)$, where $\mathrm{E}^{\mathrm{glu}}$ Tracer is the enrichment of plasma $\left[\mathrm{U}_{-}{ }^{13} \mathrm{C}_{6}\right]$ glucose $\left(M_{6}\right)$ determined by GC/MS analysis. In the basal state, HGP equals basal glucose disposal, with clearance defined as (HGP/[basal glucose]). The infusion rate $\left(\mathrm{mg} \mathrm{kg}^{-1} \mathrm{~min}^{-1}\right)$ was: miniosmotic pump rate (calibrated as above) $\times\left[\mathrm{U}_{-}{ }^{13} \mathrm{C}_{6}\right]$ glucose concentration $(0.25 \mathrm{mg} / \mu \mathrm{l}) /$ mouse body weight $(\mathrm{kg})$.

Glucose recycling refers to the ability of $\left[\mathrm{U}_{-}{ }^{13} \mathrm{C}_{3}\right]$ lactate produced from the $\left[\mathrm{U}^{13} \mathrm{C}_{6}\right.$ ] glucose to re-circulate as glucose having one, two or three ${ }^{13} \mathrm{C}$ atoms $\left(M_{1}, M_{2}\right.$ or $M_{3}$ glucose). The fraction of glucose recycled $(\mathrm{F})$ refers to recycled glucose molecules in the blood $=\left[0.5\left(M_{1}+M_{2}+M_{3}\right)\right] /[0.5$ $\left.\left(M_{1}+M_{2}+M_{3}\right)+M_{6}\right]$. The factor of 0.5 compensates for the ability of $\left[\mathrm{U}_{-}{ }^{13} \mathrm{C}_{6}\right]$ glucose $\left(M_{6}\right)$ to produce two molecules of labelled lactate for recirculation, while $M_{1}, M_{2}$ or $M_{3}$ glucose will produce one labelled lactate molecule. GC/MS conditions, sample preparations for GC/MS analysis and a detailed description of equations and calculations for HGP, glucose recycling and lipolysis can be found in our previous paper [7].

Determination of muscle glycogen content Whole quadriceps muscle was isolated from animals (killed after $5 \mathrm{~h}$ of re-feeding after a $12 \mathrm{~h}$ overnight fast) and homogenised in ice-cold $6 \%(\mathrm{wt} / \mathrm{vol}$.) perchloric acid. The resultant lysate was spun at $1,000 \mathrm{~g}$ for $20 \mathrm{~min}$ and supernatant fraction containing glycogen was saved. Glycogen was then precipitated with five volumes of ice-cold $100 \%$ (vol./vol.) ethanol and left on ice overnight at $4{ }^{\circ} \mathrm{C}$ to ensure complete precipitation. The precipitate was collected by spinning at 4,000 $\mathrm{g}$ for $20 \mathrm{~min}$. Ethanol precipitation was repeated one more time to remove any free glucose. The resulting clean glycogen, was dissolved in $0.1 \mathrm{~mol} / 1$ sodium acetate buffer $(\mathrm{pH} 4.5)$ and incubated overnight at $37^{\circ} \mathrm{C}$ in $50 \mu \mathrm{l}$ amyloglucosidase. Glycogen hydrolysed to glucose by the overnight enzyme reaction was quantified for glucose colorimetrically using a glucose assay reagent (Quantichrom, catalogue number DIGL-200; Bioassay Systems, Hayward, CA, USA).

Immunoblot analysis Whole quadriceps muscle was isolated from animals (killed as above) and homogenised in icecold lysis buffer $(50 \mathrm{mmol} / \mathrm{l}$ Tris, $\mathrm{pH} 7.5,150 \mathrm{mmol} / \mathrm{l} \mathrm{NaCl}$, 1\% Triton X-100 (vol./vol.), 1 mmol/1 EDTA, 1 mmol/1 phenylmethylsulfonyl fluoride, $0.25 \%$ sodium deoxycholate (wt/vol.), $1 \mathrm{mmol} / 1 \mathrm{NaF}, 1 \mathrm{mmol} / 1 \mathrm{Na}_{3} \mathrm{VO}_{4}$ and $2 \mathrm{mmol} / 1 \mathrm{Na}_{4} \mathrm{P}_{2} \mathrm{O}_{7}$ ) containing a protease inhibitor mixture (Roche Diagnostics, Indianapolis, IN, USA). The resultant lysates were centrifuged for $60 \mathrm{~min}$ at $16,000 \mathrm{~g}$ and at $4{ }^{\circ} \mathrm{C}$, and protein concentrations were quantified using bicinchoninic acid protein assays (Pierce, Rockford IL, USA). The protein samples $(30 \mu \mathrm{g})$ were separated on $8 \%$ gradient SDS-PAGE gel and transferred to polyvinylidene difluoride membranes using a semidry electroblotter (Bio-Rad, Hercules, CA, USA). Membranes were immunoblotted with a GLUT4 polyclonal antibody (East Acres Biologicals, Southbridge, MA, USA) and GLUT1 antibody (Cell Signaling Technology, Danvers, MA, USA). Signals were visualised and quantified using the an infrared system (Odyssey Western Blotting System; Li-Cor, Lincoln, NE, USA).

Body composition This was determined for each animal by low-resolution nuclear magnetic resonance. Percentage lean mass and fat mass were calculated as a proportion of the animal's total body weight. MKR and FVB/N-wt male mice were examined.

Indirect calorimetry Measurements of oxygen consumption $\left(\dot{V} \mathrm{O}_{2}\right), \mathrm{CO}_{2}$ production and respiratory exchange ratio (RER) were performed using an indirect calorimetry system (Oxymax; Columbus Instruments, Columbus, OH, USA). Mice ( $n=8$ per genotype) were individually housed in the chamber for $48 \mathrm{~h}$ with lights on from 06:00 to 18:00 hours and an ambient temperature of 22 to $24^{\circ} \mathrm{C}$. Animals had free access to food during the dark (feeding phase 19:00 07:00 hours) and light (fasting phase 07:00-1900 hours) cycles. Gas exchange measurements were made under Oxymax system settings as follows: air flow, $0.6 \mathrm{l} / \mathrm{min}$; sample flow, $0.5 \mathrm{l} / \mathrm{min}$; settling time, $6 \mathrm{~min}$; measuring time, $3 \mathrm{~min}$.

Biochemical/serum analyses The plasma glucose level was determined with an analyser (Cobas Mira; Roche, Montclair, NJ, USA) using a reagent (Glucose UV Reagent, catalogue number 80017; Raichem, San Diego, CA, USA). Plasma insulin was determined using an ultra-sensitive rat/ mouse insulin ELISA kit (catalogue number 90060; Crystal Chem, Downers Grove, IL, USA). 
Fig. 1 Indirect calorimetry of MKR (black symbols) and FVB/N (white symbols) mice during the diurnal cycle (with free access to food [Adlib]) and the fasted to fed transition $(5 \mathrm{~h})$. During the diurnal cycle, the light or dark cycle was $12 \mathrm{~h}$ in duration. a Oxygen consumption $\left(\dot{V} \mathrm{O}_{2}\right)$ is expressed as $\mathrm{ml}$ of $\mathrm{O}_{2}$ consumed per kilogram of body weight per min and reflects energy expenditure. b Carbon dioxide consumption $\left(V \mathrm{CO}_{2}\right)$ is expressed as $\mathrm{ml}$ of $\mathrm{CO}_{2}$ produced per kilogram of body weight per min. c RER $\left(=\dot{V} \mathrm{CO}_{2} / \dot{V} \mathrm{O}_{2}\right)$ has no units and reflects fuel utilisation. d Activity was expressed by movementinduced beam interruptions per minute in the calorimeter. Data are mean \pm SEM. $* p<0.05$, $* * p<0.01, * * * p<0.001$ for MKR vs FVB/N mice
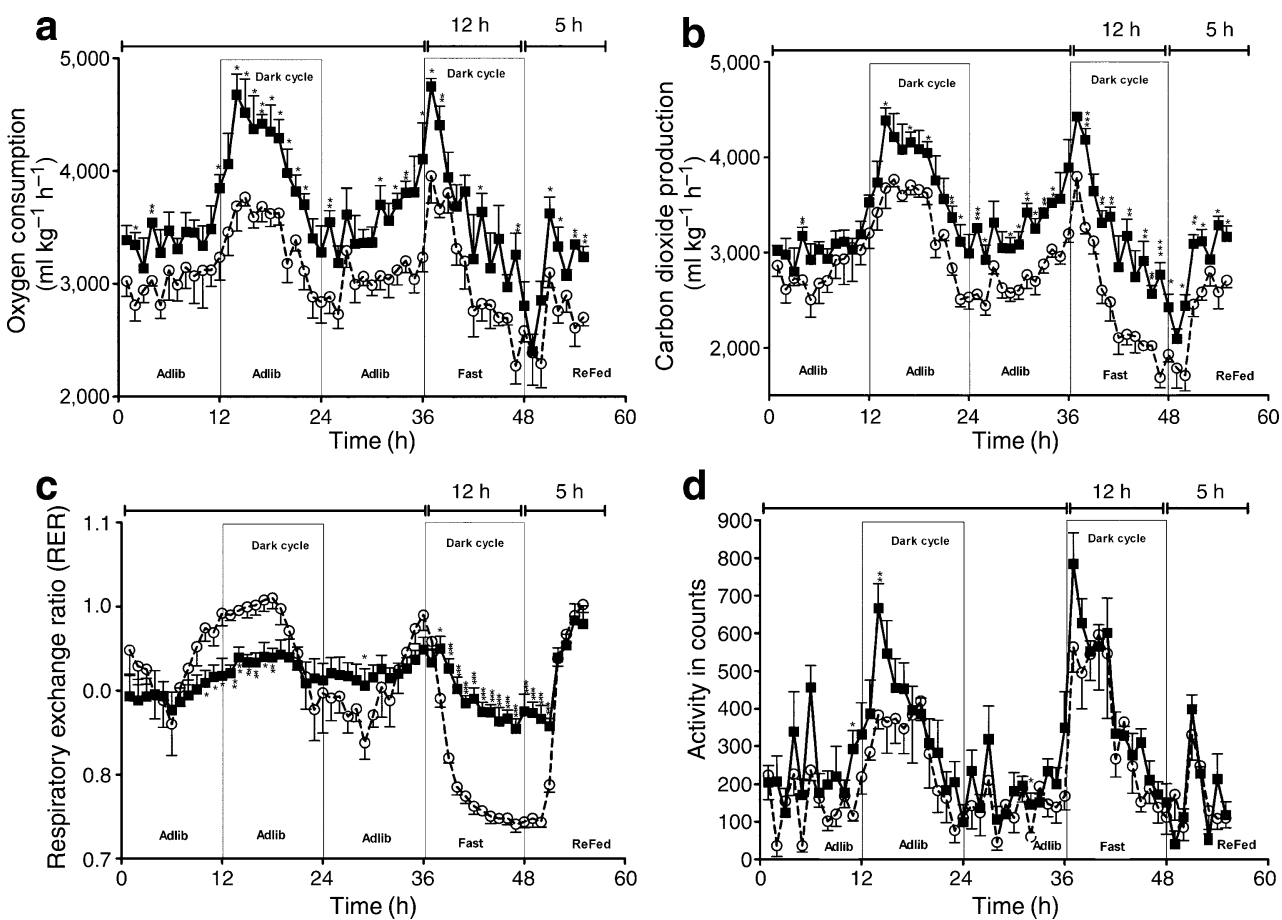

Lipid content analysis (diacylglycerol [DAG] and TAG) was performed using thin layer chromatography (TLC) as described [11]. Briefly, the whole quadriceps was isolated from animals (killed as above) and weighed. Bligh-Dyer extraction for tissue lipid was performed and the extracted lipid was evaporated under $\mathrm{N}_{2}$ in glass tubes to dryness. The lipids were re-dissolved in chloroform/methanol/acetic acid/water (25:15:4:2) normalised by the weight of the quadriceps taken to $1 \mathrm{mg} / \mathrm{ml}$ solvent. From each sample, $50 \mu \mathrm{l}$ was spotted to the respective lane on a silica gel plate (Whatman Partisil K6). TLC was then performed using the conventional three solvent system.

ATPase was assessed by the method of Round et al. at $\mathrm{pH}$ 9.4, under which condition type I (slow twitch, oxidative) muscle fibres appear light and type II (fast twitch, glycolytic) fibres dark [12]. Histological analyses of mitochondria were performed by examining activity stains of cytochrome $c$, which stains type I fibres more darkly than type II.

Statistical analyses All data are expressed as mean \pm SEM. Analyses for the significance of differences were performed using the Student's $t$ test.

\section{Results}

MKR mice are metabolically inflexible Figure 1 shows indirect calorimetry results for MKR and $\mathrm{FVB} / \mathrm{N}$ mice. Indirect calorimetry indicated that metabolic inflexibility is present in MKR mice. Mice usually consume only $20 \%$ of their total food intake during the light cycle, which usually results in a stable fasting RER that is appreciably lower than the fed RER. However, the RER of wild-type (FVB/N) and MKR mice began to rise in the middle of the light cycle, possibly indicating increased feeding during the light cycle. The total amount of food eaten over $24 \mathrm{~h}$ by MKR and FVB/N mice was similar (data not shown). Therefore, we also fasted both mouse groups for a $12 \mathrm{~h}$ period. Examination of the $12 \mathrm{~h}$ fast, followed by re-feeding, showed that MKR mice had a significantly higher RER in the $12 \mathrm{~h}$ fasted state (RER 0.884 for MKR vs 0.774 for wild-type mice, $p<0.0001$ ), but not in the $5 \mathrm{~h}$ re-fed state (RER 0.95 vs 0.978 ), indicating that MKR mice use more carbohydrate in the fasted state than FVB/N mice. $\mathrm{O}_{2}$ consumption and $\mathrm{CO}_{2}$ production were also found to be increased in MKR mice throughout most of the diurnal

Table 1 General body composition, and basal glucose and insulin in FVB/N and MKR mice

\begin{tabular}{lll}
\hline Characteristic & FVB/N & MKR \\
\hline$n$ & 6 & 5 \\
Body weight $(\mathrm{g})$ & $33 \pm 0.8$ & $27 \pm 0.1^{* * *}$ \\
Per cent body fat $(n=9)$ & $26 \pm 1.3$ & $16.8 \pm 0.8^{* * *}$ \\
Lean mass $(n=9)$ & $23 \pm 0.8$ & $20 \pm 0.22^{*}$ \\
Plasma glucose $(\mathrm{mmol} / \mathrm{L})$ & $10.93 \pm 0.18$ & $10.24 \pm 0.42$ \\
Plasma insulin $(\mathrm{pmol} / \mathrm{L})$ & $152 \pm 15.7$ & $211 \pm 18.2^{*}$ \\
\hline
\end{tabular}

Data are mean \pm SEM, unless otherwise indicated

${ }^{*} p<0.05, * * * p<0.001$ for $\mathrm{FVB} / \mathrm{N}$ wild-type vs MKR mice 
Table 2 Biochemical variables during $\left[2-{ }^{13} \mathrm{C}\right]$ glycerol infusion studies using osmotic mini-pumps

\begin{tabular}{|c|c|c|c|c|}
\hline \multirow[t]{2}{*}{ Variable } & \multicolumn{2}{|c|}{$\mathrm{FVB} / \mathrm{N}(n=5)$} & \multicolumn{2}{|l|}{$\operatorname{MKR}(n=5)$} \\
\hline & $18 \mathrm{~h}$ fast & $5 \mathrm{~h}$ re-fed & $18 \mathrm{~h}$ fast & $5 \mathrm{~h}$ re-fed \\
\hline Plasma glucose (mmol/l) & $10.67 \pm 0.17$ & $10.38 \pm 0.23$ & $13.43 \pm 1.0^{*}$ & $27.7 \pm 2.25 * * * \mathrm{a}$ \\
\hline Plasma insulin $(\mathrm{pmol} / \mathrm{l})$ & $147 \pm 18$ & $596 \pm 135^{\mathrm{b}}$ & $846 \pm 139 * *$ & $2302 \pm 53 * * * \mathrm{c}$ \\
\hline HGP from glycerol (mg kg $\mathrm{kgin}^{-1}$ ) & $2.34 \pm 0.3$ & $0.53 \pm 0.1$ & $5.15 \pm 2.2$ & $0.80 \pm 0.3$ \\
\hline
\end{tabular}

Data are mean \pm SEM

Plasma was analysed after $18 \mathrm{~h}$ fasting and then after $5 \mathrm{~h}$ of re-feeding during the study

${ }^{*} p<0.05,{ }^{* *} p<0.01, * * * p<0.001$ for FVBN wild-type vs MKR; ${ }^{a} p<0.05$ for MKR fasted vs fed; ${ }^{\mathrm{b}} p<0.01$ for FVBN wild-type fasted vs fed; ${ }^{c} p<0.0001$ for MKR fasted vs fed

cycle. There was no difference in activity between the mice (Fig. 1).

Static flux measurements indicate that MKR mice have significant secondary hepatic and adipose insulin resistance Adult MKR mice were lean, with a $20 \%$ reduction in fat mass and a $10 \%$ reduction in lean mass (Table 1). Further, MKR mice had similar basal glucose and a 50\% increase in basal insulin levels (Table 1). These observations suggest increased basal adipose and hepatic insulin resistance.

Hepatic and adipose insulin resistance was therefore assessed using stable isotopes. Table 2 and Fig. 2 summarise results for the assessment of glycerol production (reflecting lipolysis) using a mini-pump infusion of $\left[2-{ }^{13} \mathrm{C}\right]$ glycerol. Glycerol production in MKR mice was significantly increased $(p<0.05)$ in the fasted state (Fig. 2), indicating a higher rate of basal lipolysis (insensitive to suppression by fourfold increased plasma insulin) in the MKR mice, a sign of significant secondary adipose tissue insulin resistance. MKR mice also displayed a trend toward increased HGP from glycerol during fasting, suggesting increased glucose and glycerol cycling in the fasted state. Upon re-feeding, glycerol production also reflects triacylglycerol hydrolysis in the gut. Glycerol production and HGP from glycerol were comparable between $\mathrm{MKR}$ and $\mathrm{FVB} / \mathrm{N}$ mice. MKR mice showed increased plasma glucose and insulin in the fed state as compared with $\mathrm{FVB} / \mathrm{N}$ mice.

The increased glucose utilisation during a $12 \mathrm{~h}$ fast led us to assess HGP during an $18 \mathrm{~h}$ fast using osmotic minipumps with $\left[\mathrm{U}_{-}{ }^{13} \mathrm{C}_{6}\right]$ glucose (Table 3 ). In the fasted state, HGP equals basal static glucose disposal [6]. HGP was similar in MKR and FVB/N mice, but basal insulin was threefold higher, with similar levels of plasma glucose and clearance (Table 1). This indicates a significant degree of hepatic insulin resistance in MKR mice for these static, constant glucose infusion conditions.

The fraction of glucose recycled (F) refers to the ability of $\left[{ }^{13} \mathrm{C}_{3}\right]$ lactate produced from the $\left[\mathrm{U}_{-}{ }^{13} \mathrm{C}_{6}\right]$ glucose to recirculate as glucose having one, two or three ${ }^{13} \mathrm{C}$ atoms (see the Methods). This fraction was significantly lower in MKR mice (28\% MKR mice vs $35 \% \mathrm{FVB} / \mathrm{N}, p<0.05)$, consistent with more muscle/liver Cori cycling (see the Discussion).

Increased dynamic glucose disposal during SipGTT occurs in MKR mice despite higher levels of skeletal muscle DAG and TAG The increased reliance of MKR mice on carbohydrate as a primary fuel as shown by indirect calorimetry (Fig. 1) led us to examine glucose disposal in these mice. We assessed glucose disposal by doing a SipGTT using $\left[6,6-{ }^{2} \mathrm{H}_{2}\right]$ glucose. Glucose disposal was determined by assessing the rate of disappearance of $\left[6,6-{ }^{2} \mathrm{H}_{2}\right]$ glucose from the time of injection. Figure 3 shows the time course of the changes in plasma total glucose, $\left[6,6-{ }^{2} \mathrm{H}_{2}\right]$ glucose and insulin levels during the SipGTT in MKR vs FVB/N mice. The integrated changes in plasma total glucose, $\left[6,6{ }^{2} \mathrm{H}_{2}\right]$ glucose and insulin are expressed as AUC (Fig. 3). During the SipGTT, the AUC for plasma total glucose was similar for both mouse groups. The AUC for the change from basal plasma insulin was not statistically significant for MKR and FVB/N mice. However, the AUC for plasma $\left[6,6-{ }^{2} \mathrm{H}_{2}\right]$ glucose was decreased in MKR mice $(5.6 \pm 0.12 \mathrm{mmol} / \mathrm{l}$ for $\mathrm{FVB} / \mathrm{N}$ vs $4.0 \pm 0.16 \mathrm{mmol} / \mathrm{l}$ for MKR, $p<0.01)$. This implies that dynamic glucose disposal, determined by the disappear-

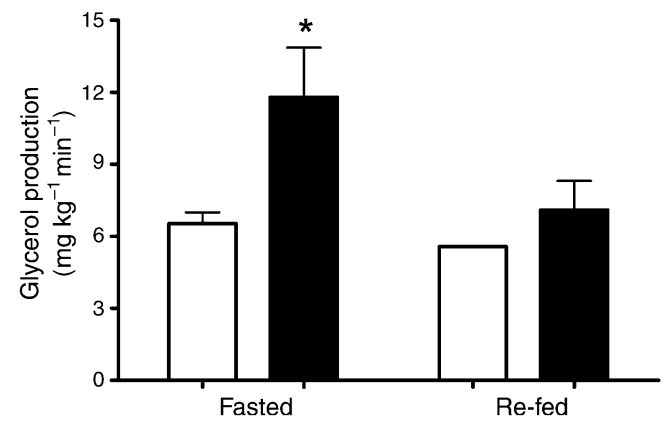

Fig. 2 Glycerol production, which represents in vivo lipolysis, was measured after $18 \mathrm{~h}$ of fasting, and also after $5 \mathrm{~h}$ of re-feeding in the $\mathrm{FVB} / \mathrm{N}$ (white bars) and MKR (black bars) mice, using a $\left[2-{ }^{13} \mathrm{C}\right]$ glycerol infusion administered by mini-osmotic pump. Glycerol production rate is expressed as $\mathrm{mg}$ of glycerol produced as indicated. Data are mean \pm SEM. ${ }^{*} p<0.05 ; n=5$ for MKR and $\mathrm{FVB} / \mathrm{N}$ mice 
Table 3 Biochemical variables during $\left[\mathrm{U}^{13} \mathrm{C}_{6}\right]$ glucose infusion studies using osmotic mini-pumps

\begin{tabular}{lll}
\hline Variable & FVBN & MKR \\
\hline$n$ & 5 & 5 \\
Plasma glucose (mmol/l) & $13 \pm 0.6$ & $11 \pm 0.6^{*}$ \\
Plasma insulin (pmol/1) & $299 \pm 24$ & $899 \pm 167^{* *}$ \\
Plasma $M_{6}$ enrichment $(\%)^{\mathrm{a}}$ & $3.3 \pm 0.5$ & $4.7 \pm 0.5$ \\
HGP (mg kg $\left.\mathrm{min}^{-1}\right)^{\mathrm{b}}$ & $35.2 \pm 9$ & $26 \pm 3.4$ \\
Glucose recycled $(\mathrm{F}, \%)$ & $35.6 \pm 2$ & $28.6 \pm 2^{*}$ \\
Plasma glucose clearance (mg/min) & $13.1 \pm 2$ & $14.5 \pm 3$ \\
\hline
\end{tabular}

Unless otherwise indicated, data are mean \pm SEM

Plasma was analysed after $18 \mathrm{~h}$ of fasting; mini-pump infusion was for the last $15 \mathrm{~h}$ of fasting

${ }^{\mathrm{a}} M_{6}$ enrichment is per cent of $\left[\mathrm{U}_{-}{ }^{13} \mathrm{C}_{6}\right]$ glucose in blood; ${ }^{\mathrm{b}} \mathrm{HGP}$ is static basal glucose disposal

${ }^{*} p<0.05,{ }^{* *} p<0.01$ for $\mathrm{FVB} / \mathrm{N}$ wild-type vs MKR mice

ance rate of $\left[6,6-{ }^{2} \mathrm{H}_{2}\right]$ glucose during the SipGTT, was greater for the MKR mice, providing evidence to suggest that skeletal muscle glucose disposal may be increased during a glucose tolerance test in MKR mice. Therefore, we sought to perform confirmatory studies of alterations in skeletal muscle metabolism and histology.

Analysis of MKR muscle (quadriceps) in the $5 \mathrm{~h}$ re-fed state (following an overnight fast) showed that MKR mice had significantly more glycogen (Fig. 4b) and increased levels of the GLUT1 and GLUT4 (Fig. 4a, c).

Figure 5a shows the analysis of muscle lipids in both mouse groups by TLC. MKR mice had increased muscle DAG and TAG levels (Fig. 5b, c). Histological activity assays (Fig. 6) show increased type II muscle fibres (darkly stained fibres) in MKR soleus muscle, as assessed by visualisation of ATPase at $\mathrm{pH} 9.4$ [12]. These muscle fibre findings for soleus muscle are consistent with the mild overall decrease in histological visualisation of soleus cytochrome $c$ activity and the increase in soleus type II (glycolytic) fibres (Fig. 6).

\section{Discussion}

A number of studies have shown that MKR mice have whole-body insulin resistance, as assessed by constantinfusion, static glucose clamp methods [1, 3, 13-17]. The MKR mouse is an excellent model of the metabolic syndrome and type 2 diabetes, as it allows assessment of progressive effects in specific tissues (liver and adipose) in response to a primary defect in muscle insulin sensitivity [1]. The $\mathrm{FVB} / \mathrm{N}$ background is unique in being able to mount an adequate pancreatic insulin secretory response, maintaining basal glucose levels even under the stress of a constant, low-level substrate infusion for prolonged periods (see Tables 2 and 3).

Our study indicates that MKR mice have a unique form of metabolic inflexibility, in which carbohydrate is always preferred as fuel source despite hyperlipidaemia, and dynamic glucose disposal is increased, while an increase in basal insulin preserves basal glucose disposal. This suggests that metabolic inflexibility in metabolic syndrome patients may be a form of compensation that allows energy needs of muscle to be maintained, despite impairments in fatty acid oxidation.

Non-invasive quantitative nuclear magnetic resonance demonstrated that MKR mice have a large reduction in fat mass with a small change in lean mass (Table 1). One hypothesis consistent with previous work showing hyperlipidaemia in MKR mice $[1,3,13,16,18]$ is that MKR mice have a higher rate of lipolysis. Here, glycerol production studies, using mini-pump infusion of a $\left[2-{ }^{13} \mathrm{C}\right]$ glycerol, showed that MKR mice did indeed have increased glycerol production in the fasted state (Fig. 2). This suggests that adipose insulin resistance with increased lipolysis in the fasted state is at least one factor in the decreased fat mass seen in MKR mice (Table 1). This increase in lipolysis can contribute to hyperlipidaemia, as skeletal muscle fatty acid oxidation is impaired (Fig. 1). Previous studies [3] have shown that Ucp 3 mRNA expression is impaired in MKR muscle and have also demonstrated the inability of MKR
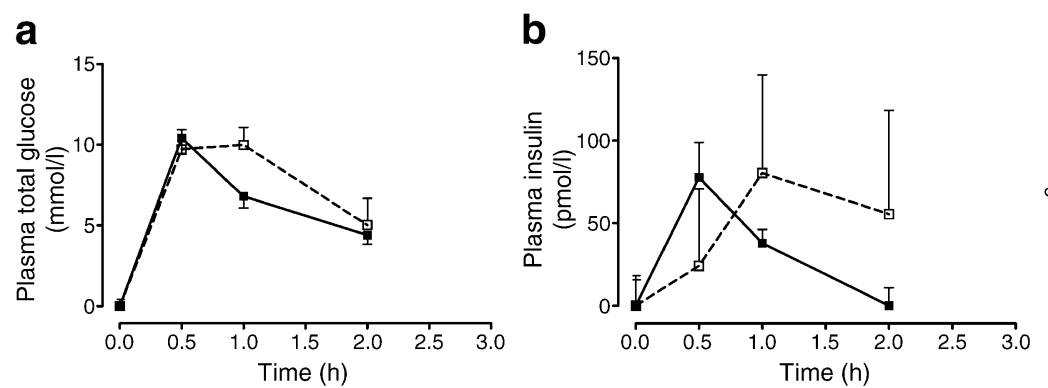

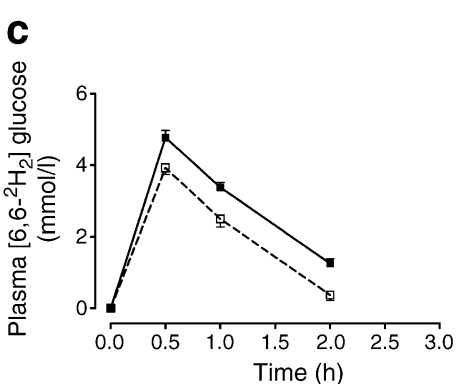

Fig. 3 Glucose disposal measured during the SipGTT in chow-fed, overnight-fasted MKR mice (white symbols) vs FVB/N controls (black symbols). Time courses shown are for plasma glucose ( $\Delta$ in basal unlabelled glucose) (a), insulin ( $\Delta$ from basal insulin concentration) (b) and $\left[6,6-{ }^{2} \mathrm{H}_{2}\right]$ glucose (c) deviations from basal levels. Each point represents the mean \pm SEM, $n=6$ and $n=5$ for FVB/N and MKR mice, respectively. Integrated responses for the AUC were: (1) plasma glucose $12.5 \pm 0.6(\mathrm{FVB} / \mathrm{N}), 15 \pm 1.1(\mathrm{MKR}), p>0.05$, (2) plasma insulin $67 \pm$ $10.3(\mathrm{FVB} / \mathrm{N}), 100 \pm 48.6(\mathrm{MKR}), p>0.05$, (3) plasma $\left[6,6-{ }^{2} \mathrm{H}_{2}\right]$ glucose $5.6 \pm 0.12(\mathrm{FVB} / \mathrm{N}), 4 \pm 0.16(\mathrm{MKR}), p<0.01$ 


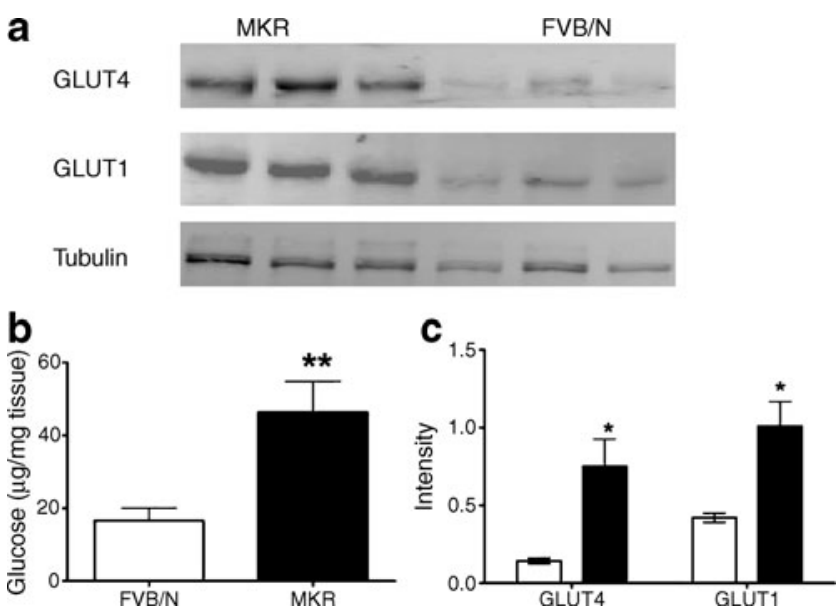

Fig. 4 Fed muscle (quadriceps) levels of GLUT1 and GLUT4 in immunoblot (a) and quantified (c), and (b) bar graph of glycogen content in FVB/N and MKR mice. Muscle was dissected $5 \mathrm{~h}$ after refeeding following a $12 \mathrm{~h}$ overnight fast. Glycogen (b) is expressed as glucose released per $100 \mathrm{mg}$ quadriceps muscle, $n=6$ per group. c Values for GLUT are in arbitrary intensity units normalised to tubulin and expressed as mean \pm SEM. Black bars, MKR; white bars, FVB/N. $n=3$ per group for each of GLUT1 and GLUT4 analysis. ${ }^{*} p<0.05$, $* * p<0.01$

muscle to oxidise fatty acids [3, 17]. Moreover, MKR mice have also been shown to be adiponectin-resistant despite normal expression of adiponectin receptors and normal AMPK phosphorylation in muscle and liver [19].

Previously MKR mice have been shown to have exaggerated basal and glucose-stimulated insulin secretion due to beta cell hyperplasia, mediated by an increased number of proliferating beta cells [3] and by beta cell dysfunction [20]. While basal glucose levels are similar, whether or not $\left[\mathrm{U}_{-}{ }^{13} \mathrm{C}_{6}\right]$ glucose is infused, the higher basal insulin seen in our MKR mice during stable isotope infusion studies (Tables 2 and 3) may be secondary to the

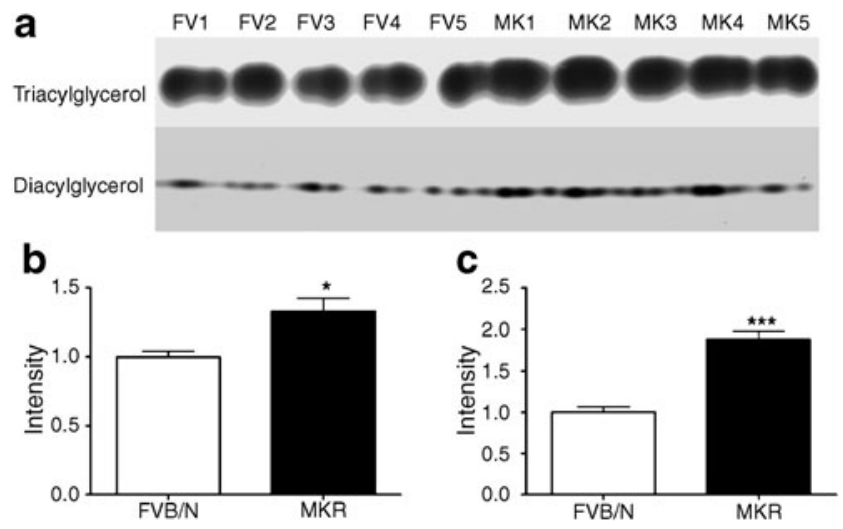

Fig. 5 Intramuscular (quadriceps) TAG and DAG assessment, using TLC. Muscle was dissected $5 \mathrm{~h}$ after re-feeding following a $12 \mathrm{~h}$ overnight fast. a TLC of DAG and TAG. b Quantative change in MKR DAG (b) and TAG (c) levels vs FVB/N, expressed in arbitrary intensity units. Data $(\mathbf{b}, \mathbf{c})$ are mean $\pm \mathrm{SEM} ; n=5$ for both groups; ${ }^{*} p<0.05, * * * p<0.001$

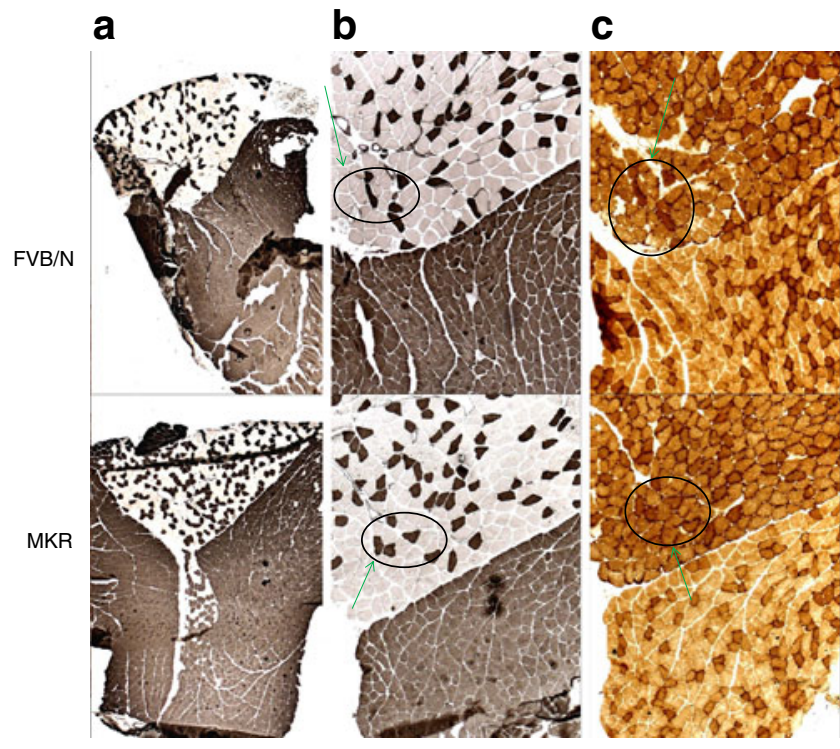

Fig. 6 Histological analysis of gastrocnemius muscle from $\mathrm{FVB} / \mathrm{N}$ and MKR mice. Muscle was dissected $5 \mathrm{~h}$ after re-feeding following a $12 \mathrm{~h}$ overnight fast. a ATPase $\mathrm{pH} 9.4$ staining, magnification $\times 4$, of FVB/N and MKR samples as indicated. At pH 9.4, light coloured fibres are type I, dark coloured fibres are type II. Symbol, soleus muscle group; the rest of each slide shows the gastrocnemius muscle group. b Staining as above (a), but with magnification $\times 10$ for ATPase $\mathrm{pH} 9.4$ staining. c Cytochrome $c$ staining of gastrocnemius muscle, at magnification $\times 10$. Intensity of brown staining indicates degree of cytochrome $c$ oxidase activity. Circled areas (with arrows) indicate corresponding sections of ATPase and cytochrome $c$ stains

response of insulin-resistant MKR mice to the mass of glucose in the stable isotope infusion itself. Infusion of stable isotopes differs from infusion of radioactive tracers, in that appreciable mass is infused, which is subtracted from the appearance rate (see the Methods). The rate of tracer infusion was set to be no more than 5 to $10 \%$ of estimated HGP [7]. But even this slow infusion apparently invokes a high insulin response in MKR mice in order to maintain a fairly normal basal glucose level. Despite the threefold higher basal insulin resulting from $\left[\mathrm{U}_{-}{ }^{13} \mathrm{C}_{6}\right]$ glucose infusion, HGP was not suppressed in MKR mice, indicating hepatic insulin resistance.

Furthermore, the use of $\left[\mathrm{U}_{-}{ }^{13} \mathrm{C}_{6}\right]$ glucose to measure HGP has an additional advantage over previous radioactive tracer studies of HGP in MKR mice [1, 3, 13, 15, 17]. [U- ${ }^{13} \mathrm{C}_{6}$ ]Glucose measurement of HGP also gives an estimate of Cori (glucose/lactate) cycling. Cori cycling is mainly due to liver-muscle flux interactions. The fraction of glucose recycled (F) was lower for MKR mice. This observation is consistent with glucose being the primary fuel for MKR muscle. In MKR mice, glucose may be metabolised to a greater degree in muscle down to the level of $\mathrm{CO}_{2}$, rather than being partially utilised to form lactate, as suggested from RER measurements during indirect calorimetry (Fig. 1). 
The static $\left[\mathrm{U}_{-}{ }^{13} \mathrm{C}_{6}\right]$ glucose mini-pump infusion data (Table 3) are consistent with previous euglycaemic-hyperinsulinaemic clamp studies indicating both hepatic and peripheral insulin resistance $[1,3,13,15,17]$. Yet indirect calorimetry indicated greater glucose utilisation despite this insulin resistance. The SipGTT revealed enhanced glucose disposal in the Ppar $\alpha$-null mouse model while the euglycaemic-hyperinsulinaemic clamp was unable to show this [6]. Our SipGTT results for MKR vs FVB/N mice in Fig. 3 indicate a seeming paradox of increased dynamic glucose disposal during the SipGTT, despite increased static glucose disposal. Even though the euglycaemichyperinsulinaemic clamp and stable isotope mini-pump substrate infusions are consistent with decreased glucose disposal, the results are static, constant infusion measurements. In contrast, the SipGTT assesses dynamic glucose disposal during the fasted to fed transition [6]. As observed by indirect calorimetry (Fig. 1), the SipGTT results support the notion that glucose is the primary fuel utilised by MKR mice, even in the fasted state, resulting in metabolic inflexibility. Figure $4 \mathrm{~b}$ shows that fed MKR muscle accumulated significantly more glycogen; they also showed increased levels of GLUT1 and GLUT4 (Fig. 4a, c), supporting other measurements (Fig. 1, Fig. 3) that suggest MKR muscle may have increased glucose utilisation.

Our results also indicate that static and dynamic measurements of whole-body insulin resistance and glucose disposal are complementary [6]. Static and dynamic measurements of glucose disposal seem to be better correlated with different whole-body and tissue assessments. In this study, static measurements of glucose disposal, whether by euglycaemic-hyperinsulinaemic clamps or in response to constant, stable isotope minipump infusions, appear to reflect intramuscular, lipiddependent insulin resistance. Dynamic glucose disposal, as assessed by SipGTT, may correlate better with the indirect calorimetric assessment of fuel utilisation that defines metabolic flexibility.

The increased dynamic glucose disposal in MKR mice may also reflect unique aspects of metabolic physiology in this mouse. MKR insulin resistance is associated with decreased fatty acid oxidation in muscle and is very responsive to PPAR $\alpha$ administration [3] and leptin treatment [17]. Our studies of deficient PPAR $\alpha$ action [4, 6, 7] suggest a common compensatory use of glucose when fatty acid utilisation is diminished, at least in MKR and Pparoknockout mouse models.

The MKR mouse has been shown to have changes in the levels of transcription factors that determine myogenesis early in life [2]. This early effect may result in the formation of more type II ( glycolytic, as well as oxidative) fibres in a normally type I (primarily oxidative) muscle group (soleus; Fig. 6), helping to adapt the MKR mouse for greater glucose utilisation. It is possible that early adaptive changes to compensate for insulin resistance may predispose an organism to metabolic inflexibility later in life. Certainly new paradigms accounting for the differences in static and dynamic glucose disposal may be necessary, if an integrated view of insulin resistance and metabolic inflexibility is to be achieved.

Acknowledgements This work was supported by NIH grants 2R01DK058132 (principal investigator I. J. Kurland) and 5R01-CA12879902 (principal investigator D. LeRoith). The authors thank R. S. Sellers, Director, AECOM Histology and Comparative Pathology Facility, for supervising the histopathology work done in the Histology Facility for this study.

Duality of interest The authors declare that there is no duality of interest associated with this manuscript.

\section{References}

1. Fernandez AM, Kim JK, Yakar S et al (2001) Functional inactivation of the IGF-I and insulin receptors in skeletal muscle causes type 2 diabetes. Genes Dev 15:1926-1934

2. Fernandez AM, Dupont J, Farrar RP, Lee S, Stannard B, Le Roith D (2002) Muscle-specific inactivation of the IGF-I receptor induces compensatory hyperplasia in skeletal muscle. J Clin Invest 109:347-355

3. Kim H, Haluzik M, Asghar Z et al (2003) Peroxisome proliferator-activated receptor-alpha agonist treatment in a transgenic model of type 2 diabetes reverses the lipotoxic state and improves glucose homeostasis. Diabetes 52:1770-1778

4. Xu J, Chang V, Joseph SB et al (2004) Peroxisomal proliferatoractivated receptor alpha deficiency diminishes insulinresponsiveness of gluconeogenic/glycolytic/pentose gene expression and substrate cycle flux. Endocrinology 145:1087-1095

5. Haluzik M, Gavrilova O, LeRoith D (2004) Peroxisome proliferator-activated receptor-alpha deficiency does not alter insulin sensitivity in mice maintained on regular or high-fat diet: hyperinsulinemic-euglycemic clamp studies. Endocrinology 145:1662-1667

6. Vaitheesvaran B, Chueh FY, Xu J et al (2010) Advantages of dynamic "closed loop" stable isotope flux phenotyping over static "open loop" clamps in detecting silent genetic and dietary phenotypes. Metabolomics 6:180-190

7. Xu J, Xiao G, Trujillo C et al (2002) Peroxisome proliferatoractivated receptor alpha (PPARalpha) influences substrate utilization for hepatic glucose production. J Biol Chem 277: 50237-50244

8. Xu J, Lee WN, Xiao G et al (2003) Determination of a glucosedependent futile recycling rate constant from an intraperitoneal glucose tolerance test. Anal Biochem 315:238-246

9. Xu J, Gowen L, Raphalides C et al (2006) Decreased hepatic futile cycling compensates for increased glucose disposal in the Pten heterodeficient mouse. Diabetes 55:3372-3380

10. Xu J, Lee WN, Phan J, Saad MF, Reue K, Kurland IJ (2006) Lipin deficiency impairs diurnal metabolic fuel switching. Diabetes 55:3429-3438

11. Kupke IR, Zeugner S (1978) Quantitative high-performance thinlayer chromatography of lipids in plasma and liver homogenates after direct application of 0.5 -microliter samples to the silica-gel layer. J Chromatogr 146:261-271 
12. Round JM, Matthews Y, Jones DA (1980) A quick, simple and reliable histochemical method for ATPase in human muscle preparations. Histochem J 12:707-710

13. Heron-Milhavet L, Haluzik M, Yakar S et al (2004) Musclespecific overexpression of $\mathrm{CD} 36$ reverses the insulin resistance and diabetes of MKR mice. Endocrinology 145:4667-4676

14. Zhao H, Yakar S, Gavrilova O et al (2004) Phloridzin improves hyperglycemia but not hepatic insulin resistance in a transgenic mouse model of type 2 diabetes. Diabetes 53: 2901-2909

15. Pennisi P, Gavrilova O, Setser-Portas J et al (2006) Recombinant human insulin-like growth factor-I treatment inhibits gluconeogenesis in a transgenic mouse model of type 2 diabetes mellitus. Endocrinology 147:2619-2630

16. Kim H, Haluzik M, Gavrilova O et al (2004) Thiazolidinediones improve insulin sensitivity in adipose tissue and reduce the hyperlipidaemia without affecting the hyperglycaemia in a transgenic model of type 2 diabetes. Diabetologia 47:2215-2225

17. Toyoshima Y, Gavrilova O, Yakar S et al (2005) Leptin improves insulin resistance and hyperglycemia in a mouse model of type 2 diabetes. Endocrinology 146:4024-4035

18. Kawashima Y, Chen J, Sun H et al (2009) Apolipoprotein E deficiency abrogates insulin resistance in a mouse model of type 2 diabetes mellitus. Diabetologia 52:1434-1441

19. Kim CH, Pennisi P, Zhao H et al (2006) MKR mice are resistant to the metabolic actions of both insulin and adiponectin: discordance between insulin resistance and adiponectin responsiveness. Am J Physiol Endocrinol Metab 291:E298-E305

20. Asghar Z, Yau D, Chan F, Leroith D, Chan CB, Wheeler MB (2006) Insulin resistance causes increased beta-cell mass but defective glucose-stimulated insulin secretion in a murine model of type 2 diabetes. Diabetologia 49:90-99 